\title{
A física da literatura: \\ concretude, imaginação e contenção em Antonio Candido
}

Anita Martins Rodrigues de Moraes $^{a}$

\begin{abstract}
Resumo
Desenvolvo, neste trabalho, apontamentos sobre Os parceiros do Rio Bonito (1964), de Antonio Candido, destacando a ideia de que a cultura caipira estaria em vias de desaparecimento. Traço paralelos entre tal diagnóstico e a leitura que Antonio Candido faz d'Os sertões (1902), de Euclides da Cunha, considerando especialmente o artigo "Euclides da Cunha, o sociólogo" (1952). Avanço, então, no sentido de alguns questionamentos acerca das funções atribuídas à literatura por Candido, especialmente no que se refere ao contexto latino-americano, marcado pelo subdesenvolvimento, recorrendo a aspectos da Formação da Literatura Brasileira (1959) e ao ensaio "Literatura, espelho da América?" (1995). Pretendo lidar, assim, com os perigos que, para o autor, a própria literatura ocidental se via desafiada a enfrentar. Proponho, enfim, que Antonio Candido entende ser a literatura uma delicada operação que envolve forças diversas, como a da realidade concreta ou corpórea, a da sociabilidade, a força da imaginação e a força das próprias palavras e sua carga simbólica, configurando-se, em minha perspectiva, uma espécie de física da literatura. Para tanto, analiso comentários do autor acerca da zoofilia caipira, dos perigos da masturbação e da imaginação, comentários presentes na "Parte Complementar" d'Os parceiros do Rio Bonito.

Palavras-chave: literatura latino-americana; literatura regionalista; subdesenvolvimento; primitivismo; imaginação.
\end{abstract}

Recebido em: 26/08/2018 Aceito em: 17/11/2018

aDepartamento de Ciências da Linguagem da Universidade Federal Fluminense (UFF). E-mail: anitademoraes@ gmail.com 
James Clifford, em A experiência etnográfica (1998), chamou a atenção para uma estrutura recorrente da etnografia, a do lamento pelo fim iminente da sociedade estudada, algo que denominou alegoria do resgate (CLIFFORD, 2008, p. 78-79). Clifford lida com a escrita de antropólogos como Malinowski, Radcliffe-Brown e Evans-Pritchard, autores fundamentais para Antonio Candido. Pretendo, aqui, apresentar uma leitura d'Os parceiros do Rio Bonito (1964), destacando justamente o motivo do desaparecimento da cultura caipira, representante de um modo de vida concebido como organicamente integrado ao mundo natural. Meu objetivo é avançar no sentido de alguns questionamentos acerca das funções atribuídas à literatura por Candido, especialmente no que se refere ao contexto latinoamericano. ${ }^{1}$ Trata-se de lidar, enfim, com o rendimento (e a possível inversão) de tal alegoria do resgate em Candido, de maneira a considerar os perigos de desaparecimento que, em sua perspectiva, a própria literatura se via desafiada a enfrentar.

Em A tradição esquecida: Os parceiros do Rio Bonito e a sociologia de Antonio Candido (2002), Luiz Carlos Jackson sugere que Os sertões (1902), de Euclides da Cunha, consiste em referência fundamental para Candido, sendo a leitura que desenvolve em "O sociólogo em Euclides da Cunha" (comunicação apresentada em evento comemorativo em São

${ }^{1}$ Sobre a participação de Antonio Candido em debates sobre literatura e cultura na América Latina, conferir publicação de sua correspondência com Angel Rama (CANDIDO; RAMA, 2016). Conferir também Revista Chilena de Literatura: Dossiê sobre Antonio Candido (Número 97; 2018), volume organizado por Mónica González, e o artigo "Trilhos que se bifurcam: formação e inserção entre Candido e Rama", de Eduardo Andrés Mejía Toro (2016).

${ }^{2}$ Conforme apreciação de Luiz Carlos Jackson, o artigo publicado em 1952 repõe, com poucas alterações, o conteúdo d a comunic a ção proferida em 1947 (JACKSON, 2002, p. 68). José do Rio Pardo em 1947; texto inédito) e "Euclides da Cunha, sociólogo", publicado no jornal O Estado de São Paulo, em 1952, atestados de tal apreço. ${ }^{2}$ De fato, há nítida continuidade entre a perspectiva trágica dos "dois Brasis", sugerida por Candido, nesse artigo, como própria de Euclides, e a tese do isolamento caipira que desenvolvia em seu doutoramento. Vejamos como a tópica do isolamento é formulada por Candido em sua leitura d'Os sertôes:

Como sabemos, um dos maiores fatores da evolução social é a difusão de cultura, a comunicação de traços culturais de um grupo a outro. Euclides ilustra este fenômeno com eloqüência, ao descrever a autonomia cultural do caboclo nordestino. Premido por um meio adusto, isolado da civilização pelo deserto, pelo regime de propriedade, pela política metropolitana; isolado do seu semelhante pela fraca densidade demográfica - voltou-se sobre si mesmo e elaborou, com os parcos elementos de que dispunha, o equipamento mínimo para sobreviver. Os sertões descrevem a sua roupa de couro, espécie de couraça; descrevem os poucos 
objetos que fabrica - a rede de caroá, a bolsa de caça, a sela tosca, o cacete cheio de chumbo; descrevem os que recebeu do litoral - foice, faca de ponta, espingarda, bacamarte, esporas; falam da sua dieta bárbara, de paçoca ameríndia; da arca e dos dois ou três tamboretes que lhe mobiliam a casa frágil. Aí está o acervo da cultura material. Da cultura espiritual, um catolicismo adaptado ao meio, misturado de fetichismo, consistindo em ritos propiciatórios - os mais necessários para quem luta contra a seca - e chegando a criar um santo próprio, um santo profissional: São Campeiro.

Esta cultura rude, fruto da segregação social, não pode, por isso mesmo, evoluir. Tendo criado o mínimo para ajustar-se ao meio, o sertanejo se aferra a este mínimo, enquanto as populações litorâneas, uma centena de quilômetros além, estão centenas de anos à sua frente. É o caso típico daquilo que, depois de Ogburn [sociólogo americano; 1886-1959], se chama em sociologia demora cultural. Euclides analisa largamente o fenômeno, a fim de mostrar sua conseqüência lógica: o conflito. De fato, quando uma cultura em estado de demora entra bruscamente em contacto com padrões evoluídos, surge uma situação de antagonismo, que se resolve na luta pela preservação dos valores antigos, de um lado, e a superimposição de valores novos, do outro. O desfecho é quase sempre aceleramento de mudança na cultura dominada, com a difusão maior ou menor dos traços da cultura dominante. É o que vemos todos os dias nos fatos da colonização européia, foi o que Euclides viu, estudou e compreendeu na tragédia de Canudos. (CANDIDO, 2002, p. 177-178). ${ }^{3}$

O isolamento surge, por um lado, associado a uma cultura de mínimos, noção decisiva para Candido em sua avaliação da sociedade caipira (fundada, em sua perspectiva, em mínimos vitais), inclusive no que se refere à dieta "bárbara", ou indígena, atestando precariedade e pobreza material. Por outro lado, o isolamento aponta para um drama: a dissociação produzida entre interior e litoral tem como consequência inevitável o conflito. Vemos que a colonização europeia é lida nessa chave, a do encontro trágico, sendo associada ao massacre de Canudos. Nota-se que não é propriamente a colonização europeia motor de violência, mas a discrepância entre padrões evoluídos e culturas rudes. Nesse sentido, no caso de Canudos, a causa

${ }^{3}$ A ortografia desta citação foi preservada, mantendo-se como aparece no original consultado. da tragédia estaria no próprio isolamento, ou seja, numa colonização incompleta. Assim, desgarradas da civilização, as populações do interior do país se viram absorvidas pelo mundo natural, recorrendo, então, aos modos de vida indígenas. 
Uma dupla tragédia se armava para tais populações: de um lado, Candido sugere uma condição trágica constitutiva da rusticidade e do primitivismo, devedora de um supostamente parco aparato civilizacional, ou seja, a vida do interiorano se via regida pelas forças da natureza (nesse sentido, a vida humana se via refém de forças exteriores e imensas [CANDIDO, 2002, p. 181]); de outro lado, uma tragédia talvez ainda mais pungente: o penoso, brutal e inevitável conflito dessas populações com padrões culturais mais evoluídos. O conflito trágico arma-se, assim, como decorrência de uma suposta demora cultural. Não é difícil notar que posteriormente será a noção de subdesenvolvimento decisiva para que Candido articule a heterogeneidade cultural ao problema da desigualdade social (brasileira, em particular, e latino-americana, em geral), repondo, assim, a ideia da demora cultural. Tenho em mente, obviamente, seu texto "Literatura e subdesenvolvimento", cuja primeira veiculação data de 1970, e acuso sua perspectiva evidentemente etapista: destaco a afirmação de que há no país amplas camadas da população mergulhadas "numa etapa folclórica de comunicação oral" (CANDIDO, 2006b, p. 171).

Lembremos que a famosa "Nota Preliminar" a Os sertões já delineia a tese da necessária extinção de sertanejos e caipiras. Diz, então, Euclides da Cunha:

O jagunço destemeroso, o tabaréu ingênuo e o caipira simplório serão em breve tipos relegados às tradições evanescentes, ou extintas. Primeiros efeitos de variados cruzamentos, destinavam-se talvez à formação dos princípios imediatos de uma grande raça. Faltou-lhes, porém, uma situação de parada, o equilíbrio, que lhes não permite mais a velocidade adquirida pela marcha dos povos neste século. Retardatários hoje, amanhã se extinguirão de todo. A civilização avançará nos sertões impelida por essa implacável "força motriz da História" que Gumplowicz, maior do que Hobbes, lobrigou, num lance genial, no esmagamento inevitável das raças fracas pelas raças fortes. A campanha de Canudos tem por isto a significação inegável de um primeiro assalto, em luta talvez longa. (CUNHA, 2001, p. 66).

Em sua leitura d'Os sertões, Candido ressalta a clarividência de Euclides da Cunha, capaz de, apesar de seu arcabouço teórico rácico (e racista), desenvolver uma visão reveladora do país. De outra maneira: para Candido, o que Euclides 
observou acertadamente foram problemas de natureza social, de maneira que o conteúdo sociológico de sua obra superaria possíveis equívocos de um determinismo rácico e mesológico. Assim, se traduzirmos a tese da guerra entre raças superiores e inferiores (levando ao "esmagamento inevitável" destas) para conflito entre culturas superiores e inferiores (em termos de "imposição cultural"), traçamos a ponte entre Euclides da Cunha e Antonio Candido. Esse empenho em traduzir o racial em sociológico ou cultural, e mesmo em acentuar a perspectiva sociológica já inscrita na abordagem de Euclides da Cunha, encontra paralelo no tratamento dado por Candido ao pensamento de Sílvio Romero. Também n'O método crítico de Sílvio Romero (1954), argumentos rácicos são recuperados em termos sociológicos, sendo, então, valorizados (Candido atribui também a Romero laivos de "clarividência" [CANDIDO, 2006c, p. 168-169]). Talvez possamos mesmo pensar que o "branco" ou "ariano" de Romero torna-se, em Candido, o "europeu" ou "ocidental" - de maneira que o branqueamento como destino certo (e desejável) para um Romero ressurge em Candido como (desejável, mesmo que não tão certa) participação de todos os brasileiros nos bens culturais de matriz europeia (tenho em mente aqui a contundente defesa do amplo acesso, como formulada especialmente no famoso ensaio "O direito à literatura", de 1988).

Gostaria, contudo, de chamar a atenção para a ideia de uma dupla tragédia elaborada por Candido com base em Euclides da Cunha: como disse já, a absorção da vida humana no meio natural, configurando-se culturas primitivas (indígenas) e rudes (do caipira, do sertanejo, do interiorano em geral), leva a uma condição trágica porque o homem se vê subordinado por forças que não pode (não consegue) dominar; há, contudo, caráter trágico também no brusco encontro com estágios culturais avançados, levando a conflito violento (como no caso de Canudos) ou a convivência conflituosa e penosa (como no caso dos caipiras). Seja açoitado pela natureza, seja esmagado pela civilização, o interiorano parece ameaçado.

${ }^{4}$ Sobre O método crítico de Sílvio Romero, conferir capítulo final de Para além das palavras (MORAES, 2015).
Num caso, a ameaça é, obviamente, a natureza inclemente; no outro, consiste no ritmo expansivo da civilização, que não aguarda, não espera, não acolhe. Lembremos que, ao final de seu livro, Euclides afirma: 
Aquela criança era, certo, um aleijão estupendo. [...] Nove anos de vida em que se adensavam três séculos de barbaria. Decididamente era indispensável que a campanha de Canudos tivesse um objetivo superior à função estúpida e bem pouco gloriosa de destruir um povoado dos sertões. Havia um inimigo mais sério a combater, em guerra mais demorada e digna. Toda aquela campanha seria um crime inútil e bárbaro, se não se aproveitassem os caminhos abertos à artilharia para uma propaganda tenaz, contínua e persistente, visando trazer para o nosso tempo e incorporar à nossa existência aqueles rudes compatriotas retardatários. Mas, sob a pressão de dificuldades exigindo solução imediata e segura, não havia lugar para essas visões longínquas do futuro. O ministro da Guerra, depois de se demorar quatro dias em Queimadas removendo os últimos entraves à mobilização das forças, seguiu para Monte Santo. (CUNHA, 2001, p. 682).

O objetivo superior, trazer à civilização nossos compatriotas retardatários, evidentemente não se realizara, dando lugar à matança. Tal crime, denunciado enfaticamente, mostra-se revelador:

Revelou que pouco nos avantajávamos aos rudes patrícios retardatários. Estes, ao menos, eram lógicos. Insulado no espaço e no tempo, o jagunço, um anacronismo étnico, só podia fazer o que fez - bater, bater terrivelmente a nacionalidade que, depois de o enjeitar cerca de três séculos, procurava levá-lo para os deslumbramentos da nossa idade dentro de um quadrado de baionetas, mostrando-lhe o brilho da civilização através do clarão de descargas. (CUNHA, 2001, p. 502).

A guerra criminosa desnuda violenta clivagem do país e denuncia a reversão da civilização em barbárie. Ainda que Euclides da Cunha tenha iniciado seu livro com a tese da guerra entre as raças como força motriz da história, defende, como possibilidade irrealizada, a incorporação não violenta de uma população abandonada por séculos. Assim, não se trata de defender a manutenção do sertanejo em sua condição de retardatário, mas de desejar integrá-lo para seu próprio bem. Talvez mais: Euclides da Cunha entendeu ser o sertanejo um tipo homogêneo já configurado, de modo que seu extermínio destruiria a possibilidade de uma nova raça, genuinamente brasileira. A contrapartida desse tipo homogêneo era o mestiço do litoral (incluindo o soldado), ainda instável como tipo, marcado pela heterogeneidade, pela 
desarmonia. Outra tragédia, talvez ainda mais terrível, então se desnuda: a destruição do futuro país, ou seja, o cancelamento da possibilidade de uma civilização futura de fato brasileira. O próprio país parece depender, para se constituir como nação civilizada, da sutura entre litoral e interior, de uma sutura que propicie a incorporação do rústico na civilização, mas que garanta também a aclimatação da civilização (ocidental), sua estabilização nessa nova terra. De outra maneira: Euclides da Cunha parece desejar que um jogo de forças mais equilibrado tome o lugar da guerra criminosa, dosando-se a mestiçagem descontrolada (litorânea) com a estabilidade do mestiço do interior (já equilibrado como tipo).

Se avançarmos na sugestão de que Candido recupera a perspectiva de Euclides da Cunha (além da de Romero), traduzindo, em termos sociológicos, o que se formulava também em termos raciais, teremos delineadas as ideias norteadoras d'Os parceiros do Rio Bonito (talvez também as da Formação da literatura brasileira, de 1959). A ideia de extinção, de desaparecimento inevitável, convive com o desejo de incorporação e síntese, ou seja, com o desejo de que o conflito entre mundo civilizado e rústico seja contornado pela incorporação deste, evitando-se a perturbação violenta e a destruição total. No caso d'Os parceiros, há também um crime que se denuncia: a proletarização do caipira, o transtorno de seus modos de vida pelo contato com a cultura urbana, sem que lhe sejam oferecidas condições para dela participar de modo pleno e equilibrado - condições que seriam possibilitadas pela reforma agrária. Assim, ao denunciar o êxodo rural indiscriminado e pauperizante, Candido defendia o amplo direito do pobre do interior à propriedade da terra, acompanhada da garantia de acesso a modos de plantio mais modernos e eficientes de modo que o caipira superasse o instinto em favor da racionalidade (CANDIDO, 1971, p. 166; 168). Se a cultura caipira estava fadada a desaparecer, já que condicionada por modos rudimentares e instintivos de produção (associados ao modo de vida indígena), a modernização do interior paulista (episódio do progresso da civilização ou de sua inevitável expansão) deveria ser organizada em benefício do próprio caipira, não apenas das elites. Tratava-se de vislumbrar uma modernização em bases socialistas, que corrigisse a barbárie da modernização capitalista, sua exploração brutal, reificadora e excludente. 
Há, contudo, talvez mais: o homem do interior e sua cultura rústica poderiam também contribuir para a aclimatação da civilização nos trópicos, servindo como espécie de contrapeso a tendências europeizantes que caracterizariam os espaços urbanos. Tal aposta é delineada por Candido em outros momentos, sendo suas reflexões acerca do regionalismo na literatura brasileira (e latinoamericana em geral) particularmente importantes. Entendo haver, então, ambivalência nas ponderações de Candido, dados os perigos múltiplos que vislumbra. Falei já da condição trágica de retardatário do caipira isolado em seu rincão, desgarrado da civilização, aproximando-se sobremaneira à condição dos animais e vegetais (CANDIDO, 1971, p. 123, p. 176) e do índio (CANDIDO, 1971, p. 82) em sua luta diária pela sobrevivência. Trata-se, para Candido, de uma vida consumida pelas necessidades materiais, havendo pouco espaço para os produtos do espírito (no limite, chegando a "pouco desenvolvimento mental" [CANDIDO, 1971, p. 43]). É de se destacar, nesse sentido, que inicialmente sua pesquisa de doutorado voltava-se para o estudo do cururu, dança caipira que, em sua perspectiva, seria de base tupi - como argumenta no precioso artigo publicado em 1956: “Cururu: Possíveis raízes de uma dança popular" (CANDIDO, 1999b). Contudo, dada justamente a suposta continuidade entre bases econômicas e produção cultural na sociedade rústica (como na primitiva), decide estudar as condições de vida do caipira, lidando, especialmente, com o problema da alimentação (CANDIDO, 1971, p. 9). Tal imediaticidade entre base material e produção cultural seria própria dos estágios primitivo e rústico, não se dando, para o autor, em âmbito civilizado.

Em "Estímulos da criação literária" (terceiro capítulo de Literatura e sociedade, de 1965), Candido avança na comparação entre poesia primitiva e civilizada (esses são seus termos), apontando a presença imediata do alimento em sua concretude (ou "realidade nutricional") na primeira, e defendendo que, na segunda, surge apenas já desrealizado, ou seja, como símbolo ou objeto estético. Tal diferença apontaria não só para distintos estímulos da produção poética (corporais, no caso primitivo, e espirituais, no caso civilizado), mas também para uma diferença na relação do homem com a realidade concreta: o poeta primitivo lida com a realidade natural mesma; o civilizado 
parte já de um conjunto de elaborações, lida com concepções de natureza elaboradas pela cultura (trata-se de uma natureza já estilizada, transfigurada). Ou ainda: o civilizado parte de um acervo cultural; o primitivo trava embate direto com o mundo, sua palavra deve negociar com a realidade concreta mesma, sem considerável mediação prévia. Daí a passagem tida como tão natural por Candido em seu estudo da cultura caipira: da dança à base material - ou, mais especificamente, do estudo do cururu, possivelmente tendo sua origem na dança indígena do sapo (como Candido explica em artigo já mencionado), ao estudo de suas condicionantes. Reitero: a cultura civilizada não seria imediatamente condicionada pela base material; a rústica e a primitiva, sim.

É então que noto ambivalência: por um lado, a condição trágica de homem absorvido por forças da natureza, submetido por elas, leva ao desejo de sua integração ao mundo civilizado, à cultura urbana, como forma de emancipação, de lhe proporcionar desenvolvimento mais pleno de suas potencialidades humanas (ou espirituais); por outro, essa mesma cultura urbana, em permanente contato com "influxos de civilização" estrangeiros, pode descambar em produções incaracterísticas e em artificialismo, para o que a estabilidade interiorana, alcançada em bases indígenas, serviria como contrapeso. Assim, não se trata apenas de "salvar" o caipira de sua condição trágica constitutiva; tratase também de, incorporando o caipira (ou o interiorano em geral), resistir aos perigos, às armadilhas da própria civilização em expansão. Contra o artificialismo da vida civilizada, o pendor do interiorano à concretude do mundo natural resulta surpreendente antídoto.

Já na Formação, tal ambivalência se delineia: o romance é tanto instrumento de descoberta e interpretação, recurso para uma elaboração primeira da realidade do país - apalpada pelo escritor romântico (CANDIDO, 1993, p. 101) que produzia, então, um primeiro substrato literário do qual outras gerações poderiam partir, como, no caso do romance urbano, faria Machado de Assis (CANDIDO, 1993, p. 102) -, quanto gênero compensatório à inflação da fantasia, que teria absorvido, em grande medida, a poesia (CANDIDO, 1993, p. 98-99). Por um lado, destina-se à estilização da realidade, que virá a elaborar em temos literários, produzindo, então, camadas mediadoras 
entre o homem e o mundo (partindo do contato direto com a realidade, que lembra a condição primitiva, propiciaria o contato indireto, mediado, próprio do civilizado); por outro lado, o romance é instrumento de resistência a outras forças, à da fantasia individual e à da palavra voltada para si mesma, enredada em relações intra e intertextuais. Assim, o romance fora fator de civilização do país, produzindo elaboração da realidade, ou seja, camadas mediadoras e transfiguradoras da realidade bruta em palavra (gradualmente, como disse já, a realidade vê-se elaborada, torna-se concepção de realidade, faz-se espiritualizada, ganha dimensão simbólica); o romance pôde, contudo, por sua vocação referencial, ser também antídoto aos descaminhos dessa mesma tendência de afastamento gradual (por elaboração, transfiguração, simbolização) da realidade de partida.

Tal afastamento não seria, então, apenas ganho (de humanização, para mantermos os termos de Candido); envolve os graves perigos do artificialismo (este também desumanizante). Não apenas a natureza absorvente boicotaria a realização da "humanidade do homem"; a própria civilização poderia desnaturá-la, corrompê-la. Se a literatura tem uma função humanizadora, conforme defende o autor em vários momentos (como em "A literatura e a formação do homem", de 1972, e em "O direito à literatura", ensaio já mencionado), lida com dois perigos, dois riscos de desumanização: o pendor para a concretude (próprio dos estágios culturais primitivo e rústico, como vimos), que cria uma zona de indistinção entre vida humana e animal; e o pendor para a fantasia sem freios e para a palavra como puro jogo, em que a vocação humana para a mediação com o mundo concreto e com a sociedade (na partilha de "valores éticos e estéticos" [CANDIDO, 1999c, p. 88]), vocação implicada na produção de sentido (simbolização) e comunicabilidade (agregação), vê-se comprometida.

Se na Formação uma dupla função do romance já se delineava, será em “Literatura, espelho da América?", de 1995, que Candido desenvolverá mais ambiciosamente tal tese, dando-lhe mais amplo alcance. Vejamos seu ponto de partida:

A literatura corresponde à necessidade universal de dar forma à fantasia, inclusive (talvez sobretudo) a fim de compreender melhor a realidade. A sua natureza reside neste paradoxo, e a respeito convém citar um estudioso 
francês: "O homo vates é pelo menos tão antigo em nós quanto o homo faber, e dos dois é o que tem mais peso na vida interior da humanidade" [Gabriel Germain. Genèse de l'Odyssé, 1954]. Trata-se, portanto, de um caso de discernimento do real por meio da deformação, do arbítrio, da alternativa fictícia, e não por meio da observação e do registro. (CANDIDO, 1999a, p. 105).

Lidando com a realidade e a fantasia, a literatura parece propiciar (e se alimentar de) seu relacionamento. Se apenas registro da realidade, pende ao documental e ao científico; se pura fantasia, perde-se no nonsense e no absurdo (CANDIDO, 1999a, p. 108). Tal pendor para a pura fantasia Candido associará tanto à subjetividade (ou subjetivismo) quanto à autorreferencialidade (em que as palavras valem e agem por si mesmas, desligadas de sua referência). Vejamos:

Outro traço devido ao Romantismo foi o que se pode chamar de tendência para a auto-destruição do discurso, que antes era concebido como instrumento de expressão, mas igualmente de comunicação, de mensagem inteligível aos que podem recebê-la. A auto-destruição significa, pelo contrário, redução drástica da comunicação em benefício da expressão, mas de uma expressão que freqüentemente visa a impor, não o recado de um indivíduo, e sim o impacto do próprio discurso, tomado como finalidade de si mesmo. Penso nos textos oriundos das tendências para o fragmentarismo, o hermetismo, a elipse, o subentendido, o absurdo. Isto pode aparecer em casos relativamente simples, como a poesia do nonsense no Romantismo brasileiro, que foi uma espécie de jogo ocasional de jovens poetas estudantes. Mas aparece também na obscuridade programada de Mallarmé e na associação livre dos surrealistas, culminando na confiança ao acaso, como no jogo combinatório chamado cadavre exquis. Ou ainda no projeto monumental de Joyce no Finnegans wake. Em muitas dessas experiências há uma espécie de superação da linguagem concebida como comunicação. O resultado são linguagens que parecem ter por finalidade a elaboração de estruturas cuja validade reside na lógica interna, não na referência, e são portanto muito mais desligadas do lugar e do tempo, visando a um espaço semântico que transcende a representação do espaço físico e social. Entretanto, nas literaturas latino-americanas o Romantismo foi em grande parte o esforço de dar expressão literária ao nosso espaço físico e social, o que não é contraditório, porque as sementes de negação do discurso comunicativo germinaram lentamente, florescendo principalmente no século XX. (CANDIDO, 1999a, p. 108). 
Candido acusa uma tendência para a autodestruição do discurso na literatura ocidental (a tal literatura civilizada de "Os estímulos da criação literária"; o grande sistema dentro do qual a literatura brasileira se formaria como subsistema, nos termos da Formação), havendo, em sua própria dinâmica interna, um grave perigo. É então que a concretude da vida caipira e sertaneja pode funcionar como freio:

Levando em conta os traços característicos do Romantismo (no sentido extenso mencionado acima), o "normal" seria que a narrativa regionalista tivesse tido o seu período áureo no século XIX e decaísse no século XX, à medida que o discurso literário tendia a se universalizar e a trocar a representação do mundo pela criação de universos verbais autônomos. No entanto, deu-se o oposto, pois a maior obra de cunho regional da narrativa brasileira, a de Guimarães Rosa, apareceu em meados do século $X X$, quando o regionalismo era geralmente considerado uma tendência superada, por ser comprometida com o pitoresco e um exotismo interno que contrariava a universalidade do discurso. (CANDIDO, 1999a, p. 110).

\section{No final de seu texto, Candido assevera:}

Parece, portanto, que nos países onde há zonas de atraso econômico e social não é possível anular a sua representação literária. Elas têm um peso vivo, impõem-se à consciência e então ocorre a fusão que Angel Rama definiu tão bem, - o universalismo das vanguardas servindo de veículo paradoxal para os particularismos tradicionais. Weidlé [Vladimir Weidlé. Les abeilles d'Aristée, 1954] pensava no sentimento religioso como referência externa que permite a coerência e a comunicação das obras por meio do estilo, que é uma unificação. A literatura dos países novos da América Latina mostra que a nação é uma poderosa referência externa que dá consistência e serve de bússola implícita ou explícita, desde a sua fase de revelação do país, pressupondo o leitor como patriota, até a sua fase de expressão universal, pressupondo o leitor, como cúmplice do discurso, visto sobretudo na sua dimensão inovadora. Isto leva a concluir que há uma relação necessária entre a organização interna da obra (concebida como "texto") e algo exterior que lhe fornece a matéria, o elemento constitutivo, que é o seu tema e representa a sua âncora na realidade do mundo, da personalidade, das idéias. Nos países da América Latina há uma equação constante entre a gratuidade e o empenho, bem clara na persistência do regionalismo em sucessivas modalidades, mesmo quando as literaturas que servem de modelo (européias, norte-americanas) já não o praticam mais em obras de alta qualidade. E essa reflexão leva a confiar na perenidade da literatura, porque ela corresponde 
a necessidades profundas e é capaz de assimilar a inovação sem perder a capacidade de representar as particularidades do contexto onde funciona. (CANDIDO, 1999a, p. 112).

A relação necessária entre organização interior da obra (o texto) e seu exterior (ou realidade de referência), ameaçada pela tendência para a autorreferencialidade própria da literatura ocidental, mantém-se vigorosa na América Latina. Trata-se de um lastro no mundo devedor do caráter empenhado de nossa literatura, empenhado, como afirma Candido desde a Formação, na própria implementação de práticas letradas e na construção das nações. Assim, na Formação, ou seja, nos momentos formativos da literatura brasileira, o grande perigo estaria na "barbárie e incultura gerais" (CANDIDO, 1964, p. 89), ao qual precisaram resistir nossos escritores - lembremos que, em "Literatura de dois gumes", de 1966, Candido falaria em "primitivismo reinante" (CANDIDO, 2006a, p. 214) em "solicitações a princípio poderosas das culturas primitivas" (CANDIDO, 2006a, p. 199) e no "perigo de absorção [da literatura] pelo universo folclore" (CANDIDO, 2006a, p. 214). No presente (final do século XX), a literatura, em todo o mundo ocidental, vê-se em perigo, ou seja, em risco de se perder diante de uma avassaladora tendência autotélica; nesse quadro, "primitivismo", "rusticidade" e "atraso econômico" funcionam como surpreendente antídoto, revelam-se a própria garantia para o bom funcionamento da literatura na América Latina. De empecilho, o subdesenvolvimento do continente reverte-se em vantagem.

Pelo exposto, nota-se que o pendor para a concretude, entendido por Candido (e Euclides da Cunha) como traço decisivo da vida primitiva e rústica, resulta ora em entrave ora em garantia para o bom funcionamento da literatura. Tal ambivalência ilumina aspectos do pensamento de Candido, a literatura seria uma gestão de equilíbrios envolvendo forças diversas: a força da realidade concreta ou material (que pode absorver e aprisionar a palavra na pura referencialidade); a força da sociabilidade (que aponta para o acervo comum, partilhado, dos recursos expressivos, tendendo, contudo, ao convencional); a força da fantasia (implicando o pendor para a subjetividade e, no limite, para a incomunicabilidade); e a força do próprio texto (que pode se desgarrar do mundo, seja 
da referência seja do autor ou destinatário, perdendo-se em puro jogo de palavras).

Tendo em conta "Os estímulos da criação literária", entendemos que tal pendor do texto para si mesmo é risco que corre apenas a escrita literária, não sendo esperado na literatura oral. Isso porque a inscrição da palavra poética numa situação performática faz do texto oral apenas um elemento entre outros (implicando o corpo do poeta - sua voz e gestualidade - e a situação coletiva de execução), não tendo, então, autonomia. Se tal autonomia é desejável (e desejada por Candido) como sinal de avanço civilizador, é, porém, tida por perigosa, pois flerta com a fantasia e a palavra-jogo. Aposta-se, como disse, em contrapesos, delineando-se uma física (mecânica? hidráulica?) da literatura. Seu bom funcionamento se mede pelo equilíbrio que possa alcançar entre forças diversas. Nesse sentido, o frequente recurso de Candido a oposições em tensão se explica - lembremos: realidade versus fantasia; documento versus ficção; grupo versus indivíduo; comunicação versus expressão; mundo interior versus mundo exterior; concretude versus simbolismo; rudimentar versus elaborado; espontâneo versus artificial; intelecto/técnica versus emoção; palavra versus mundo; interior da obra versus exterior da obra; conteúdo/ matéria versus forma; texto versus contexto; universal versus particular; nacional versus internacional; regionalismo versus cosmopolitismo, etc. Como gestão de equilíbrios, a literatura é exercício que demanda compensações, ou seja, exige que se freiem os excessos; do contrário, arrisca autodestruir-se. Assim, se o regionalismo é força antiliterária quando pende excessivamente ao documental, à realidade particular e pitoresca, age como força pró-literária quando resiste aos extremos da fantasia deformante e da palavra autorreferente, compensando tendências de alheamento. De outra maneira: ao desempenhar sua função de representação, a literatura latinoamericana (e mais fortemente a de vocação regional) resiste a excessos deletérios; a âncora na referência, ou seja, a força de atração do polo nacional-regional, parece proteger a literatura na América Latina, de maneira que, nos finais do século XX, poderíamos supor maiores riscos alhures.

Ao final d'Os parceiros do Rio Bonito, Candido traz alguns apontamentos reveladores sobre a sexualidade do jovem caipira. Vejamos: 
Desde pequenos os filhos acompanham os pais, familiarizando-se de maneira informal com a experiência destes [...]. [...] A educação sexual é igualmente espontânea. Como Dáfnis e Cloe, meninos e meninas aprendem o essencial com os animais. [...] Não tenho dados positivos que permitam avaliar o papel da masturbação, mas sou levado a crer que é, se não rara, por certo incomparavelmente menos usada que nas cidades, mesmo porque o jovem caipira tem menos estímulos eróticos e despende constantemente uma soma de energia física pouco própria ao que os antigos denominavam os trabalhos de Vênus. No entanto, quando premido pelo desejo, resta uma via, geralmente percorrida por todos: o coito com animais.

Parece que a bestialidade radica em vínculos profundos entre homem e animal, originados nas fases em que este foi domesticado e passou a viver junto ao dono, numa proximidade física e afetiva que hoje mal podemos avaliar. O homem se atribuía não raro natureza idêntica à do animal - circunstância que deve estar ligada às manifestações totêmicas e à gênese dos mitos zoomórficos. [...] No Brasil, o erotismo zoofílico é comum nas zonas rurais, tendo sido Gilberto Freyre o primeiro a chamar sobre ele a atenção dos estudiosos, tratando da formação sexual do menino de engenho. De um ponto psicossociológico, não se pode reputá-lo anormalidade. Nas fazendas e sítios, a iniciação à vida do sexo dá-se muitas vezes com animais, sendo que as novilhas, eguinhas e carneiras fixam de preferência o erotismo infantil e juvenil. A expressão eufêmica "encostar no barranco", referente ao ato sexual em geral, deriva de tais práticas e revela a sua generalidade.

Na área estudada elas são correntes, e como nem todos possuem gado de porte, os meninos e os jovens utilizam também as cabras, porcas e galinhas, mais acessíveis pela criação doméstica. Pode-se dizer que isto equivale à "masturbação compensadora" (Forel), corrente nas cidades, sendo, como ela, etapa transitória de iniciação, superada sem dificuldade aos primeiros contatos com mulher, que se estabelecem cedo devido ao casamento precoce. Num e noutro caso, apenas a incorporação definitiva aos hábitos sexuais do adulto poderia ser considerada desvio; e tudo bem pesado, a prática rural talvez seja menos nociva que a urbana, pois repousa menos na imaginação. Proporcionando ao adolescente um certo contato direto com a realidade, ela diminui o perigo de inibições e desvios, que podem desenvolver-se em relação ao ato normal do sexo. (CANDIDO, 1971, p. 249-252). 
Vemos que Candido entende como saudável prática sexual do adulto o contato efetivo do homem com uma mulher. Na infância e adolescência, a masturbação (nas cidades) e a zoofilia (nas zonas rurais) podem ser esperadas, não sendo, então, patológicas. Assim, o adulto masturbador ou zoófilo é doente; o menino e o jovem, não (sobre moças e mulheres o autor não comenta). Além da condenação da masturbação do adulto, talvez seja a tolerância com relação à zoofilia infanto-juvenil do caipira que mais chame a atenção. Destaco, contudo, um aspecto dessa tolerância: trata-se, para Candido, de prática mais sadia que a masturbação, ou "menos nociva", por uma causa notável: "repousa menos na imaginação". "Inibições e desvios" podem se instalar na vida sexual adulta em decorrência de tal masturbação imaginante.

Não podemos deixar de notar que, do mesmo modo que Candido sugere ser a atração da realidade freio aos descaminhos da literatura, aponta aqui a zoofilia como pendor para a concretude capaz de conter os perigos da imaginação, por sua vez livremente instalada na masturbação. ${ }^{5}$ Talvez possamos avançar e pensar que a função de dar forma à fantasia, atribuída por Candido à literatura, funcione também na chave da contenção. Trata-se de resistir aos perigos da fantasia largada a si mesma, de canalizá-la para o mundo. $\mathrm{Ou}$ ainda: como o jovem caipira se protegia da imaginação no coito com animais (e, quando adulto, com uma mulher), a literatura latino-americana se protege, por seu forte empenho referencial, dos desvios de uma literatura desgarrada do mundo, entregue à fantasia, enredada numa autorreferencialidade masturbatória. O escritor latino-americano, como o caipira, estaria, assim, mais protegido que outros. No caipira, a contenção da imaginação dá-se pela zoofilia infanto-juvenil; no que tange à literatura

Sobre as relações entre masturbação, escrita e imaginação, ler Gramatologia, de Jacques Derrida, especialmente o capítulo intitulado "Este suplemento perigoso...", dedicado a Jean-Jacques Rousseau (DERRIDA, 2004, p. 173-200). latino-americana, dá-se pela demanda de uma realidade marcada pelo atraso. Contra a imaginação lançada a si mesma, masturbatória, Candido defende a contenção, reafirmando o valor de uma "literatura empenhada", apostando na atração da "nação" como travão à fantasia, freio que deve salvar a literatura de si mesma. 


\section{REFERÊNCIAS}

CANDIDO, A. Formação da Literatura Brasileira: momentos decisivos (v. I). São Paulo: Livraria Martins, 1964 [1959].

. Formação da Literatura Brasileira: momentos decisivos (v. II). São Paulo: Itatiaia, 1993 [1959].

. Os parceiros do Rio Bonito. São Paulo: Livraria Duas Cidades, 1971 [1964].

. Estímulos da criação literária. In: Literatura e Sociedade. São Paulo: Publifolha, 2000 [1965].

. Euclides da Cunha, sociólogo. In: Textos de intervenção. Organização de Vinícius Dantas. São Paulo: Duas Cidades; Editora 34, 2002.

. O direito à literatura. In: . O direito à literatura e outros ensaios. Organização de Abel Barros Baptista. Coimbra: Angelus Novus, 2004.

. Literatura de dois gumes. In: . A educação pela noite. Rio de Janeiro: Ouro sobre azul, 2006a.

. Literatura e subdesenvolvimento. In: A educação pela noite. Rio de Janeiro: Ouro sobre azul, 2006b.

. O método crítico de Sílvio Romero. Rio de Janeiro: Ouro Azul, 2006c [1954].

. Literatura, espelho da América?. Revista Remate de Males: Antonio Candido (número especial), Campinas: DTLUnicamp, 1999a [1995].

. Cururu: Possíveis raízes de uma dança popular. Revista Remate de Males: Antonio Candido (número especial), Campinas: DTL-Unicamp, 1999b [1956].

A literatura e a formação do homem. Revista Remate de Males: Antonio Candido (número especial), Campinas: DTLUnicamp, 1999c [1972]. 
CANDIDO, Antonio; RAMA, Ángel. Un proyecto latinoamericano: Antonio Candido \& Ángel Rama, correspondencia. Edição, prólogo e notas de Pablo Rocca. Montevidéo: Estuario Editora, 2016.

CLIFFORD, James. A experiência etnográfica: antropologia e literatura no século XX. Rio de Janeiro: Editora UFRJ, 1998.

CUNHA, Euclides. Os sertões. Organização do texto e notas remissivas por Leopoldo M. Bernucci. São Paulo: Ateliê Editorial, 2001 [1902].

DERRIDA, Jacques. Gramatologia (1967). São Paulo: Editora Perspectiva, 2004.

GONZÁLEZ, Mónica (Org.). Revista Chilena de Literatura: Dossiê Antonio Candido. n. 97. abr. 2018.

JACKSON, Luís Carlos. A tradição esquecida: Os parceiros do Rio Bonito e a sociologia de Antonio Candido. Belo Horizonte: UFMG; São Paulo: FAPESP, 2002.

MORAES, Anita Martins Rodrigues de. Para além das palavras: representação e realidade em Antonio Candido. São Paulo: Editora da Unesp, 2015.

TORO, Eduardo Andrés Mejía. Trilhos que se bifurcam: formação e inserção entre Candido e Rama Toro. Remate de Males, 2016, n. 2. 


\section{Abstract \\ The physics of literature: concreteness, imagination and restraint in Antonio Candido}

In this paper, I develop notes on Os parceiros do Rio Bonito (1964), by Antonio Candido, highlighting the idea that the caipira's culture [country's culture] is disappearing. $I$ associate this diagnosis with the reading that Antonio Candido develops about Os sertões (1902), by Euclides da Cunha, especially considering the article "Euclides da Cunha, o sociólogo" (1952). I turn to some aspects of the functions attributed to the literature by Candido, especially with regard to the Latin American context, marked by underdevelopment, focusing on the Formação da Literatura Brasileira (1959) and on the essay "Literatura, Espelho da America?" (1995). I intend, therefore, to deal with the dangers which, for the author, Western literature itself was challenged to face. I propose, finally, that Antonio Candido understands that literature is a delicate operation that involves diverse forces, such as that of concrete or corporeal reality, that of sociability, the force of imagination and the force of words themselves and their symbolic charge, what configures, in my perspective, a kind of physics of literature. To that end, I analyse the author's comments about bestiality, about the dangers of masturbation and imagination, comments present in the "Parte Complementar" of Os parceiros do Rio Bonito.

Keywords: Latin American literature; regionalist literature; underdevelopment; primitivism; imagination. 